\title{
La historia de la ciencia: ¿Qué es y para qué?
}

\author{
History of science, what is it and whatever for?
}

\author{
Blanca Irais Uribe Mendoza*
}

Por lejanas o distantes que parezcan, la historia y la ciencia tienen una conexión indisoluble que nace en el momento mismo en que estos campos del saber se constituyen. Es por ello que en las siguientes líneas aspiro a que el lector encuentre claridad respecto a esta interesante relación, misma que se halla en el quehacer del científico. Para comenzar debemos entender qué es la historia.

La historia como una disciplina del campo de las ciencias sociales reconstruye el pasado a partir de documentos y evidencias (de tipo material y oral) que son clasificadas, valoradas, interpretadas, cuestionadas y conectadas con otros hechos, mismas que se someten a un análisis crítico con la intención de comprender y explicar las dinámicas de las sociedades del pasado. La intención del historiador al ejecutar esta tarea, es responder preguntas muy concretas que surgen desde el presente y se plantean a partir de las necesidades de su tiempo. Por lo tanto, la historiografía (que es la historia escrita desde la indagación y la reflexión del pasado) narra, describe y explica el pasado a la luz del presente.

\section{¿QUÉ ES LA HISTORIA DE LA CIENCIA?}

La historia de la ciencia no es un relato de hechos relacionados cronológicamente, tampoco es una dialéctica de problemas y soluciones de la práctica experimental, tampoco es la descripción de conjeturas y refutaciones, o del reemplazo de prácticas, teorías, conceptos o métodos. Se trata de una narrativa historiográfica que describe el proceso de transformación y evolución de la acción cognitiva humana. En ella se detalla la historicidad detrás de la experimentación y las teorías que buscan comprender, aprehender e intervenir el mundo desde los criterios de la racionalidad científica. ${ }^{1}$ En ese sentido, la historia de la ciencia explica la trayectoria que los seres humanos han seguido para hallar soluciones a problemas concretos y conocer aspectos de la realidad. ${ }^{2}$
En la narrativa de la historia de la ciencia, se detaIlan interconexiones epistémicas y sociales que constituyen un contenido diacrónico donde las transformaciones científicas y tecnológicas sólo se explican por una red de relaciones y sucesiones causales de orden económico, político, material, ambiental, cultural, religioso, espacial y epistémico.

En el carácter explicativo de la historia de la ciencia, la epistemología (que es el estudio del conocimiento) incorpora una experiencia histórica sobre la construcción, institucionalización y legitimidad de los elementos normativos de la ciencia, su contexto de justificación, su pretensión de verdad y los elementos prácticos, teóricos y metodológicos. Sin dejar de lado la explicación sociocultural del destierro o permanencia de nuevos criterios conceptuales. Por lo tanto, la historia de la ciencia es, en sentido amplio, la ciencia misma.

\section{HISTORIA DE LA CIENCIA, ¿PARA QUÉ?}

De manera consciente o no, el científico usa a la historia de la ciencia para situarse en un punto específico del desarrollo de determinado conocimiento, para luego partir de ahí hacia nuevos postulados que le conduzcan a resultados novedosos y, eventualmente, cambios de paradigma. ${ }^{3}$ Por lo tanto, la historia de la ciencia tiene la capacidad de revelar procedimientos que devienen en confrontaciones que desencadenan el avance de la ciencia.

\footnotetext{
* Doctora en Historia y Filosofía de la Ciencia-UNAM. Instituto de Investigaciones sobre la Universidad y la Educación-UNAM.
}

(C) 2017 Universidad Nacional Autónoma de México, [Facultad de Odontología]. Este es un artículo Open Access bajo la licencia CC BY-NC-ND (http://creativecommons.org/licenses/by-nc-nd/4.0/).

Este artículo puede ser consultado en versión completa en http://www.medigraphic.com/facultadodontologiaunam 
En el siglo XXI, ante el desenfreno del desarroIlo científico y tecnológico, la sociedad experimenta incertidumbre y desorientación ante la capacidad ilimitada de la ciencia y la tecnología para intervenir, modificar y rediseñar el mundo natural. Incluso hoy en día es claro que las innovaciones tecnocientíficas (de orden médico, de telecomunicaciones, de producción de alimentos y de bienes de consumo en general) están causando severos daños ambientales, sobre todo ante la vulnerabilidad para controlar innovaciones biotecnológicas. Ante esta preocupación del presente, la historia de la ciencia llega para exponer-desde el pasado- las razones o las causas culturales, políticas, económicas, espaciales y materiales por las que la ciencia y la tecnología no sólo se impusieron como un conocimiento válido para comprender y explicar el mundo, sino además, para transformarlo y comercializarlo. De manera que el presente exige a la historia análisis y explicaciones críticas que cuestionen el posicionamiento del conocimiento tecnocientífico en el mundo actual.

La historia de la ciencia también cumple la función de resguardar el patrimonio de los saberes locales. Esto quiere decir que cuando el pasado científico de una región o de un país se pulveriza o desaparece, la historia de la ciencia recupera y encuentra prácticas, teorías, propuestas y obras de momentos y lugares con la intención de ubicar originalidad, innovación e historicidad de los saberes en un tiempo y espacio específico.

En esta misma dirección sucede que en la historia de la ciencia se desentraña el proceso de construcción de una comunidad profesional y científica, por ello tiene la capacidad de despertar reconocimiento e identidad gremial. Ésa es la razón por la que en la historia de la ciencia se encuentra el ethos (conducta, carácter, identidad) del científico, ya que en la historia de la ciencia, como sucede con la historia en general, se esboza un paisaje donde los seres humanos encuentran reconocimiento e identidad. Este aspecto también se relaciona con el hecho de que la historia de la ciencia sea un espejo que refleja los términos con los que la ciencia construye las imágenes del futuro que desea alcanzar en el universo de la naturaleza y los seres humanos, de ahí que sirva para crear y administrar nuevas instituciones de educación superior y mostrar los contenidos propios de cada profesión científica ${ }^{4,5}$ y donde se encuentra, precisamente, uno de los usos de la memoria científica.

Por otra parte, la historia de la ciencia sirve para visibilizar la forma en que los seres humanos hemos establecido nuestra relación con el mundo natural a partir de los criterios que establece la racionalidad científica, así que en ella pueden hallarse las resignificaciones teóricas, prácticas, discursivas e incluso ontológicas que la producción de conocimiento otorga, en tiempo y espacio, a los seres vivos. ${ }^{6}$ De manera que la historia de la ciencia da cuenta de cómo es que los seres humanos hemos capitalizado y administrado la naturaleza desde la producción de conocimiento.

\section{A MANERA DE CONCLUSIÓN}

La historia de la ciencia es, en suma, la ciencia misma y la construcción de su campo como disciplina y profesión. En ella se explica cómo es que ésta llegó a ser lo que es, qué papel juega el científico en la sociedad, cómo es que la ciencia y los científicos han cambiado al mundo y cuáles han sido los factores por los que la ciencia se volvió un instrumento válido para comprenderlo y medirlo.

La historia de la ciencia no sólo da cuenta de la evolución cognitiva, conceptual y experimental de la ciencia, sino además, en ella se manifiesta la capacidad para explicar cómo es que la ciencia se ha ido insertando en la sociedad. En ese sentido no se divorcia de una mirada crítica a los factores que condicionan la trayectoria de la ciencia, pero tampoco deja de narrar las proezas de hombres y mujeres que han hecho del conocimiento científico la herramienta más eficaz para resolver muchos de los grandes problemas que enfrenta la sociedad.

\section{REFERENCIAS}

1. Wartofsky M. The Relation between Philosophy and Science and History of Science. Boston Studies in the Philosophy of Science, 1977; 39: 717-737.

2. Estrada MM. Entrevista a Carlos López Beltrán. En: Uribe MB. El crisol de la ciencia y la tecnología. Voces y perspectivas desde la historia y la filosofía de la ciencia. México: UNAM. 2016.

3. Solís C. Razones e intereses. La historia de la ciencia después de Kuhn. Barcelona: Paidós. 1994.

4. Palomares TE. Los grupos científicos frente a su historia. Oralidad y memoria en el Instituto de Química de la Universidad Nacional Autónoma de México. Tesis de maestría, México: FFyL-UNAM. 2007.

5. Guevara FR. El uso de la historia en el quehacer científico. Una mirada a las obras históricas del biólogo Beltrán y del fisiólogo Izquierdo, México: UNAM. 2015.

6. Uribe MB. Apuntes para la historia de la bioartefactualidad animal. El caso de Dolly. En: Linares JE, Arriaga E. Aproximaciones interdisciplinarias a la bioartefactualidad. México: UNAM. 2016

\section{LECTURAS RECOMENDADAS}

- Carr E. ¿Qué es la historia? México: Siglo XXI. 1997. Ariel, España, 2010, p. 224. 
- De Certeau M. La escritura de la historia, México: Universidad Iberoamericana, 1993.

- Galison P, Lorraine D. Objectivity. New York Cambridge, Massachussetts: Zona Books the MIT, 2007.

- Galison P, Stump JD. The disunity of Science: boundaries, contexts and power. Stanford: Stanford University Press, 1996.

- Guillaumin G. El surgimiento de la noción de evidencia. México: UNAM, 2005.
- Hartog F. Historia, memoria y crisis del tiempo. ¿Qué papel juega el historiador?". Revista Historia y Grafía. 2009; 33: 115-131.

- Martínez SF, Guillaumin G. Historia, filosofía y enseñanza de la ciencia. México: UNAM, 2005.

Dirección para correspondencia:

Blanca Irais Uribe Mendoza

E-mail: blancaurme@gmail.com 